\title{
Effect of PI3K/PKB signal pathway inhibitor wortmannin pretreatment on intestinal barrier function in severe acute pancreatitic rats
}

\author{
Qinqing Tang ${ }^{\mathrm{C}, \mathrm{D}}$, Hengyi Wang ${ }^{\mathrm{B}, \mathrm{C}}$, Xingyu Wang ${ }^{\mathrm{C}}$, Maoyong Fang ${ }^{\mathrm{E}}$, Hong Zhang ${ }^{\mathrm{A}, \mathrm{F}}$ \\ Department of Emergency, First Affiliated Hospital of Anhui Medical University, Hefei, China \\ A - research concept and design; $B$ - collection and/or assembly of data; $C$ - data analysis and interpretation; \\ $D$ - writing the article; $E$ - critical revision of the article; $F$ - final approval of the article
}

Address for correspondence

Hong Zhang

E-mail:zhanghong20070703@163.com

\begin{abstract}
Funding sources
This work was supported by grants from the International Education Project of Anhui Medical University (grant No. gjjyxm201525) of China; the Training Program of the National Natural Science Foundation of The First Affiliated Hospital of Anhui Medical University of China (grant No. 2013kj08); the Research Foundation of Anhui Medical University (grant No. 2015xkj089); and by Anhui Province Public Welfare Linkage Plan Project (grant No. 1604f0804022).
\end{abstract}

Conflict of interest None declared

Received on March 19, 2018

Reviewed on August 1, 2018

Accepted on November 21, 2018

Published online on August 12, 2019

Cite as

Tang Q, Wang H, Wang X, Fang M, Zhang H. Effect of PIJK/PKB signal pathway inhibitor wortmannin pretreatment on intestinal barrier function in severe acute pancreatitic rats. Adv Clin Exp Med. 2019;28(8):1059-1066.

doi:10.17219/acem/99910

DOI

10.17219/acem/99910

\section{Copyright}

Copyright by Author(s)

This is an article distributed under the terms of the

Creative Commons Attribution Non-Commercial License

(http://creativecommons.org/licenses/by-nc-nd/4.0/)

\begin{abstract}
Background. It is well-known that severe acute pancreatitis (SAP) due to infection is mainly caused by intestinal bacterial translocation. The intestinal barrier is tasked with preventing intestinal pathogenic bacteria and toxins from reaching the parenteral tissues through the intestinal wall. Therefore, maintaining intestinal barrier function may be the key to preventing damage from acute pancreatitis (AP). The phosphatidylinositol 3-kinase/protein kinase B pathway (PIJK/PKB) plays a role in AP. However, the exact effect of PIJK/PKB on injury associated with SAP has not yet been found.
\end{abstract}

Objectives. The present study was aimed at investigating the impact of wortmannin (WT), a PIKK/PKB inhibitor, on intestinal barrier function in SAP rats.

Material and methods. The rats were divided into 3 groups: 1) the Sham Surgery group (SS), whose duodenum and pancreas were flipped 3 times $(n=18) ; 2)$ the pancreatitis group (SAP), who were injected through retrograde pancreatic duct injection with 5\% sodium taurocholate $(n=18)$; and 3) the WSAP intervention group (SAP+WT). Serum alpha-amylase levels, plasma endogenous endotoxin, hematoxylineosin (H\&E) staining, intestinal mucosa electron microscopy, intestinal permeability, and expression of p-PKB (phosphorylated protein kinase B) were measured.

Results. In our findings under an electron microscope, the SAP group presented cell edema and mitochondrial vacuolated degeneration, sparsely arranged microvilli, tight junction damage, and widening, while the WSAP group exhibited less change and lower pancreas scores $(7.4 \pm 1.14,10.2 \pm 1.48$ and $12.0 \pm 1.58$ for $3 \mathrm{~h}, 6 \mathrm{~h}$ and $12 \mathrm{~h}$, respectively) $(\mathrm{p}<0.05)$. Furthermore, the plasma endogenous endotoxin levels and Evans blue content of the WSAP group was significantly lower at all timepoints than in the SAP group $(p<0.05)$. Western blotting showed that p-PKB expression was lower in the WSAP group than in the SAP group $(p<0.05)$. Our study suggests that WT relieves intestinal permeability changes in SAP rats and may be dose-dependent.

Conclusions. The PIJK/PKB signal pathway may involve SAP-related intestinal injuries and WT may relieve SAP intestinal injuries through the PIJK/PKB pathway.

Key words: intestinal barrier, alpha-amylase, endotoxin, acute pancreatitis, signal pathway, wortmannin 


\section{Introduction}

Severe acute pancreatitis (SAP) not only causes the death of the pancreas itself, but also leads to failure of the other organs, with a fatality rate of $30 \% .^{1,2}$ Severe acute pancreatitis patients suffer from local tissue necrosis and systemic inflammatory response, often complicated by a bacterial infection of the pancreatic tissue and by the systemic inflammatory response syndrome associated with infection and multiple organ dysfunction syndrome.

Clinical data and animal studies show that most pancreatic and peripancreatic infections are enterogenic infections caused by the translocation of intestinal bacteria and bacterial endotoxin. ${ }^{3,4}$ Severe acute pancreatitis due to infection is mainly caused by intestinal bacterial translocation, and often is closely related to therapeutic effect. ${ }^{5}$

Many studies have shown that destruction of the intestinal barrier is the basis of enterogenic SAP infection. ${ }^{6-8}$ Damage of the intestinal mucosa barrier can lead to a more permeable intestinal mucosa, bacterial and endotoxin translocation, the release of inflammatory cytokines, systemic inflammatory response syndrome, and multiple organ dysfunction syndrome. ${ }^{9}$

The intestinal barrier is tasked with preventing intestinal pathogenic bacteria and toxins from reaching the parenteral tissues through the intestinal wall. The integrity of the intestinal mucosa barrier depends on the intestinal mucosa epithelial cells and the integrity of the close connection in the intestinal mucosa barrier. The tight junction between the cells surrounds the top of the intestinal epithelial cells. Furthermore, a close connection also closes the 20-nanometer gap existing between the cells, prevents bacteria and toxins in the lumen from entering the body, and maintains a stable internal environment. Severe trauma, burn, infections, major surgery, stress, and ischemia hypoxia can lead to reduced functioning of the intestinal mucosal barrier. ${ }^{10}$

Phosphatidylinositol 3-kinase (PI3K) is a $2^{\text {nd }}$ messenger related to intracellular signal transduction. The phosphatidylinositol 3-kinase/protein kinase B pathway (PI3K/PKB) is an important signal transduction system which mediates extracellular signals and induced cellular responses, and plays an important role in inflammatory cell activation, chemotaxis, tumorigenesis, and ischemia reperfusion injury. In recent years, more and more attention has been paid to the relationship between the PI3K/PKB signaling pathway and pancreatitis. The PI3K/PKB signal transduction pathway is activated when acute pancreatitis (AP) occurs, which further activates downstream factor NF kappa B and promotes the production of a variety of inflammatory factors. This creates a cascade effect named the "inflammatory cytokines storm" which induces a systemic inflammatory response and multiple organ failure. Phosphorylated protein kinase $B(p-P K B)$ reflects the activation level of the PI3K/PKB signal pathway.
Wortmannin (WT), a potent and selective inhibitor of PI3K, was applied to inhibit the activation of PI3K and thus to prevent the activation of PKB. ${ }^{11,12}$ Evidence indicates that WT may decrease inflammatory cytokines in SAP rats and suggests its regulatory mechanisms may involve the suppression of NF-kB and p38MAPK activity. ${ }^{13}$

The aims of the study were: 1) to investigate intestinal barrier function through intestinal permeability changes; 2) to study the relationship between PI3K/PKB signal transduction pathway and SAP intestinal injuries by measuring the expression levels of P-PKB and PKB in intestinal tissue; and 3) to observe the role of WT in intestinal injury in SAP rats, as to study its possible mechanism.

\section{Material and methods}

\section{Experiment design}

All the animal use experimental protocols were approved by the Animal Care and Use Committee of Anhui Medical University (Hefei, China) and the experiments were performed in accordance with the guidelines of the committee.

Pathogen-free male Wistar rats weighing 200-300 g were provided by the Laboratory Animal Center of Anhui Medical University. The animals were housed in cages at a controlled temperature of $24^{\circ} \mathrm{C}$ and under 12-hour light-dark cycles. The animals had free access to water and food. The rats were housed 5 per cage.

The animals fasted overnight, except for free access to water, before the operation. Anesthesia (10\% chloral hydrate) was injected ip.

The rats were divided into 3 groups: 1) the Sham Surgery group (SS), in which duodenum and pancreas were flipped 3 times ( $=18) ; 2$ ) the pancreatitis group (SAP), in which animals were injected through retrograde pancreatic duct injection with $5 \%$ sodium taurocholate $(\mathrm{n}=18)$; and 3) the WSAP intervention group (SAP+WT). The WT was dissolved in dimethyl sulfoxide and stored at $-20^{\circ} \mathrm{C}$. The intraperitoneal (i.p.) injection of WT $(0.35 \mathrm{mg} / \mathrm{kg})$ was performed $4 \mathrm{~h}$ before the SAP model was established. Each group was randomly divided into 3 subgroups $(3 \mathrm{~h}$, $6 \mathrm{~h}$ and $12 \mathrm{~h}$ ) with 6 rats in each subgroup.

The operation was carried out in a sterile environment in the laboratory equipped with a super clean bench. Ten percent chloral hydrate $(3 \mathrm{~mL} / \mathrm{kg})$ was i.p. injected into the rats at 3-hour, 6-hour and 12-hour timepoints. Three milliliters of inferior vena cava blood was collected in coagulation promoting tubes. After that, it stood at room temperature for $1 \mathrm{~h}$ and was centrifuged at 3,000 rpm at $4^{\circ} \mathrm{C}$ for $15 \mathrm{~min}$. The serum samples were cryopreserved at $-20^{\circ} \mathrm{C}$ for serum alpha-amylase detection. Next, $1 \mathrm{~mL}$ of venous blood was collected in anticoagulation tubes and left standing at room temperature for $1 \mathrm{~h}$. The sample was then centrifuged at 3,000 rpm at $4^{\circ} \mathrm{C}$ for $15 \mathrm{~min}$ and the plasma was cryopreserved at $-20^{\circ} \mathrm{C}$ for detection of endotoxins. 


\section{Biochemical assays}

The assays of amylase activity in alpha-amylase were performed according to the guidelines of the alpha-amylase assay kit manufacturer (Jiancheng Technology, Shenzen, China). Sodium taurocholate from Sigma-Aldrich (St. Louis, USA) was used.

Serum samples were taken from a refrigerator set to $-20^{\circ} \mathrm{C}$ and placed into a water bath at $37^{\circ} \mathrm{C}$ for $10 \mathrm{~min}$, the serum using automatic biochemical analyzer. One milliliter of inferior vena blood was placed into the anticoagulation tube and then centrifuged for $15 \mathrm{~min}$ at 4,000 rpm in order to separate the plasma. This detection procedure was in strict accordance with the instructions from the Limulus Amebocyte Lysate (LAL) endotoxin detection kit (Associates of Cape Cod, East Falmouth, USA), and plasma endogenous endotoxin content was determined using the endpoint chromogenic method.

A 6-centimeter section of the small intestine was prepared and gently rinsed with saline. Then, one end of the small intestine was closed and ligated; a gavage needle was inserted at the other end. The intestinal tissue was then injected with $0.2 \mathrm{~mL}$ of Evans blue dye through a 1-milliliter syringe and placed into a 20-milliliter Krebs liquid beaker, under $95 \% \mathrm{O}_{2}$ and in a $37^{\circ} \mathrm{C}$ water bath. The sac tissue was removed $30 \mathrm{~min}$ later and saline intestine until the flushing fluid clarification. It was allowed to dry for $24 \mathrm{~h}$ at $37^{\circ} \mathrm{C}$; then, $1 \mathrm{~mL}$ of formamide solution was added and it was incubated at $50^{\circ} \mathrm{C}$ for $24 \mathrm{~h}$. The intestinal tissue was removed and the solution was centrifuged. Supernatant was detected using a UV spectrophotometer at a wavelength of $655 \mathrm{~nm}$. The Evans blue content was measured in the intestinal tissue according to the Evans blue standard curve.

\section{Histopathological examination}

The same parts of the pancreas and the end of the ileum tissue were taken and fixed with $4 \%$ polyformaldehyde for hematoxylin \& eosin (H\&E) staining. Ileum tissue $10 \mathrm{~cm}$ away from the blind valve was taken and the mesentery was removed. It was then washed with phosphate-buffered saline solution (PBS) and immediately put into liquid nitrogen and stored at $-80^{\circ} \mathrm{C}$. Histological examination was performed by a pathologist on sections which were assigned random numbers for blinding. The severity of pancreatitis was documented with scoring edema, hemorrhage, leukocyte infiltration, parenchymal necrosis, and fatty tissue necrosis according to Spormann's scoring system. ${ }^{14}$

\section{Electron microscopy}

The samples, about $0.5 \mathrm{~cm}$ in length, were quickly cut with a sharp scalpel from the ileocecal ileum, placed on a pre-cooled glass slide, and rapidly received 4 drops of glutaraldehyde solution at $4^{\circ} \mathrm{C}$. They were then cut into small pieces $\left(0.5-1 \mathrm{~mm}^{2}\right.$ in area) and fixed at $4^{\circ} \mathrm{C}$ in a $2.5 \%$ glutaraldehyde solution for $6 \mathrm{~h}$. After washing with PBS, 1\% osmium tetroxide was added at $4^{\circ} \mathrm{C}$ for $2 \mathrm{~h}$. The solution was dehydrated by graded alcohol washes, soaked in propylene oxide for $30 \mathrm{~min}$ and then soaked in a mixture with the equivalent content of propylene oxide and resin for $2 \mathrm{~h}$. The samples were soaked in pure resin for $2 \mathrm{~h}$ and then soaked in resin-containing solution. Next, they were placed in a $60^{\circ} \mathrm{C}$ incubator and processed for $48 \mathrm{~h}$. The samples were then cut into ultrathin sections $(70 \mathrm{~nm})$ and studied under transmission electron microscope (TEM) after being washed with water and dried.

\section{Western blot analysis of p-PKB}

The tissue protein extracts were prepared as follows. Approximately 200-300 mg of ileal tissue was removed from the mesentery and non-target tissues, and then minced on ice. The tissue had $1 \mathrm{~mL}$ of lysis buffer added to it and was placed in a glass homogenizer in ice 30-50 times. Next, the tissues were placed on ice for cooling. The homogenate was transferred to a chilled centrifuge tube and centrifuged at $4^{\circ} \mathrm{C}$ at 3,000 rpm for $10 \mathrm{~min}$, in order to extract a pellet. The supernatant was then transferred to a new pre-cooled centrifuge tube at $4^{\circ} \mathrm{C}$ and centrifuged at 14,000 rpm for $30 \mathrm{~min}$. The resulting supernatant was transferred into new tubes, packed and stored frozen.

The protein content was determined with Coomassie Blue G-250 (Thermofisher, Waltham, USA). The proteins were separated using sodium dodecyl sulfate-polyacrylamide gel electrophoresis (SDS-PAGE). After electrophoresis, the proteins in PAGE gel were transferred with electroblotting to nitrocellulose membranes $\left(40^{\circ} \mathrm{C}\right)$. An electrochemiluminescent agent was added when the strip was fully colored (about $1-2 \mathrm{~min}$ ). The film was immediately filled with dry filter paper and wrapped in plastic wrap into the rear intensifying screen. It was exposed in a darkroom for between $30 \mathrm{~s}$ and $10 \mathrm{~min}$. The Xrays were then developed.

The scan density analysis was performed as follows. The ImageJ v. 1.40 software (National Institutes of Health, Bethesda, USA) was used for quantitative analysis on the results of the western blotting. GADPH was selected as an internal reference. The gray percentages of $\mathrm{p}-\mathrm{PKB}$, $G A D P H, P K B$, and GADPH were calculated.

\section{Statistical methods}

All data was processed with SPSS v. 13.0 software (SPSS Inc., Chicago, USA) and tested for normality of distribution using the Kolmogorov-Smirnov test. Normally distributed data was expressed as mean \pm standard deviation (SD). Comparisons between control and treatment groups were made with one-way analysis of variance (ANOVA) tests and then post-hoc tests. A p-value $<0.05$ was considered statistically significant. 


\section{Results}

\section{Serum alpha-amylase detection}

The levels of serum alpha-amylase had increased, confirming the diagnosis of AP. Table 1 shows the different values of alpha-amylase in each group. Animals from the SAP group had higher levels of alpha-amylase than those in the other groups. According to the statistical analysis, there was a significant difference between the SAP group and the SS group $(\mathrm{p}<0.05)$. However, after the rats were treated with WT, their level of alpha-amylase decreased significantly (Table 1 ).

Table 1. Serum alpha-amylase of SAP rats ( $n=6$ for each timepoint, $\bar{x} \pm s$ ). The SAP group had higher levels of alpha-amylase when compared to that of the other groups. According to the statistical analysis, there was significant difference between the SAP group and the control group $(p<0.05)$. However, after wortmannin treatment, their level of alphaamylase decreased significantly

\begin{tabular}{|c|c|c|c|}
\hline Tim & \multicolumn{3}{|c|}{ Alpha-amylase [U/L] } \\
\hline Groups & $3 \mathrm{~h}$ & $6 \mathrm{~h}$ & $12 \mathrm{~h}$ \\
\hline SS & $982 \pm 125$ & $970 \pm 130$ & $983 \pm 137$ \\
\hline SAP & $1,422 \pm 102^{*}$ & $1,785 \pm 176^{*}$ & $1,986 \pm 204^{*}$ \\
\hline WSAP & $1,268 \pm 106^{*}$ & $1,143 \pm 88^{* \#}$ & $1,157 \pm 143^{\#}$ \\
\hline
\end{tabular}

${ }^{*} p<0.05$, compared to the control group; ${ }^{p}<0.05$, compared to the SAP group.

\section{Changes of plasma endotoxin levels at different time points}

The plasma endotoxin levels in the SS group at the 3-hour, 6-hour and 12-hour timepoints were 0.071 $\pm 0.009 \mathrm{EU} / \mathrm{mL}$, $0.075 \pm 0.022 \mathrm{EU} / \mathrm{mL}$ and $0.056 \pm 0.008 \mathrm{EU} / \mathrm{mL}$, respectively. The levels in the SAP group were $0.250 \pm 0.015 \mathrm{EU} / \mathrm{mL}$, $0.300 \pm 0.014 \mathrm{EU} / \mathrm{mL}$ and $0.460 \pm 0.026 \mathrm{EU} / \mathrm{mL}$, respectively. The levels in the WSAP group were $0.162 \pm 0.018 \mathrm{EU} / \mathrm{mL}$, $0.226 \pm 0.015 \mathrm{EU} / \mathrm{mL}$ and $0.238 \pm 0.023 \mathrm{EU} / \mathrm{mL}$, respectively. There were no significant differences between the different timepoints in the SS group. However, the plasma endotoxin levels of the SAP group and the WSAP group at each timepoint were significantly higher than those of the SS group ( $\mathrm{p}<0.05)$ and they gradually increased over time. Also, the endotoxin levels of the WSAP group were significantly lower at all timepoints than in the SAP group $(\mathrm{p}<0.05)$ (Table 2$)$.

\section{Pathological changes}

Under light microscopy, the SS group was observed to have complete lobular structures, no bleeding or necrosis, and no inflammatory cell infiltration (Fig. 1A). The SAP 3 h subgroup exhibited hemorrhaging (Fig. 1B). As time elapsed, the damage to the pancreas gradually increased, with edema, hemorrhaging, parenchymal
Table 2. The plasma levels of endotoxins in pancreatic rats $(E U / m L, \bar{x} \pm s$, $n=6$ ). The plasma endotoxin levels among the SAP and WSAP groups at all timepoints were significantly higher than those of the SS group $(p<0.05)$, and they gradually increased with time. The endotoxin levels of the WSAP group were significantly lower at all timepoints compared with the SAP group $(p<0.05)$

\begin{tabular}{|c|c|c|c|}
\hline Tim & \multicolumn{3}{|c|}{ Plasma endotoxin levels (EU/mL) } \\
\hline Groups & $3 \mathrm{~h}$ & $6 \mathrm{~h}$ & $12 \mathrm{~h}$ \\
\hline SS & $0.071 \pm 0.009$ & $0.075 \pm 0.022$ & $0.056 \pm 0.008$ \\
\hline SAP & $0.250 \pm 0.015^{\#}$ & $0.300 \pm 0.014^{\#}$ & $0.460 \pm 0.026^{\#}$ \\
\hline WSAP & $0.162 \pm 0.018^{*}$ & $0.226 \pm 0.015^{*}$ & $0.238 \pm 0.023^{*}$ \\
\hline
\end{tabular}

${ }^{*} \mathrm{p}<0.05$, compared to the control group; ${ }^{*} \mathrm{p}<0.05$, compared to the SAP group.

necrosis, and infiltrating inflammatory cells being observed (Fig. 1C). However, the WSAP group showed milder pancreatic pathological damage than the SAP group, with less hemorrhaging (Fig. 1D). The pathological tissue scores are shown in Table 3. Compared with the SAP groups, the WSAP groups had significantly lower histopathological scores at $3 \mathrm{~h}, 6 \mathrm{~h}$ and $12 \mathrm{~h}(\mathrm{p}<0.05)$. The morphological changes of the pancreas, including pancreatic edema, necrosis, hemorrhaging, and inflammation, were scored according to Spormann's criteria. ${ }^{14}$ We also found histopathological changes in the ileum, including irregular villi, edema and infiltration of inflammatory cells (Fig. 1F,G), while the SS group did not display those changes (Fig. 1E).

Table 3. Pancreatic tissues scores $(\bar{x} \pm s)$. Compared to the SAP group $(n=6)$, the WSAP group $(n=6)$ had significantly lower histopathological scores at $3 \mathrm{~h}, 6 \mathrm{~h}$ and $12 \mathrm{~h}(\mathrm{p}<0.05)$. The morphological changes of the pancreas, including pancreatic edema, necrosis, hemorrhage, and inflammation, were scored according to Spormann's criteria ${ }^{14}$

\begin{tabular}{|c|c|c|c|}
\hline Group & $3 \mathrm{~h}$ & $6 \mathrm{~h}$ & $12 \mathrm{~h}$ \\
\hline SAP & $10.0 \pm 1.58$ & $12.8 \pm 1.92$ & $15.4 \pm 1.14$ \\
\hline WSAP & $7.4 \pm 1.14^{*}$ & $10.2 \pm 1.48^{*}$ & $12.0 \pm 1.58^{*}$ \\
\hline
\end{tabular}

${ }^{*} p<0.05$, compared to the SAP group.

\section{Ultrastructural changes of the intestinal mucosa}

The ileal epithelial cells were observed under TEM. The epithelial cell structure of the SS group was arranged in neat rows, with intracellular organelles, mitochondria and endoplasmic reticulum structure intact (Fig. 2A). Compared with the control group, the SAP group were observed after $6 \mathrm{~h}$ to present mitochondrial vacuolated degeneration and sparsely arranged microvilli (Fig. 2B). The SAP group were observed after $12 \mathrm{~h}$ to have cell edema, mitochondrial vacuolated degeneration, sparsely arranged microvilli, tight junction damage, and widening (Fig. 2C). However, the WSAP group exhibited less change than the SAP group (Fig. 2D,E), with neatly arranged microvilli, tight junction narrowing and less edema. 

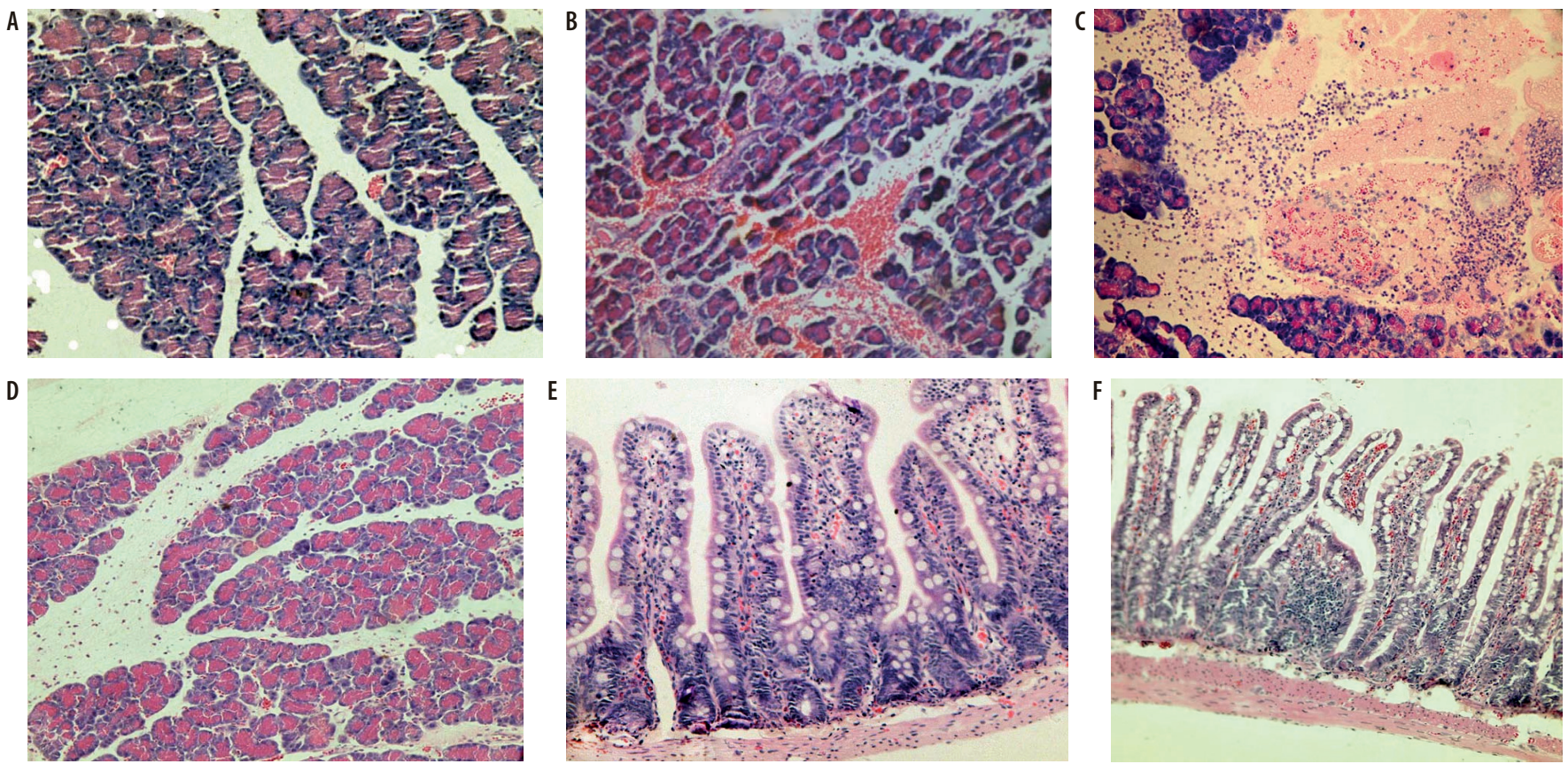

Fig. 1. Pathological changes of SAP and WSAP rats. A - SS group after $3 \mathrm{~h}$ (H\&E staining, magnification $\times 200$ ); B - SAP group after $3 \mathrm{~h}$ (H\&E staining, magnification $\times 200$ ), with interlobular hemorrhaging; C - SAP group after $12 \mathrm{~h}$ (H\&E staining, magnification $\times 200$ ), with infiltrating inflammatory cells and parenchymal necrosis; D - WSAP group after $3 \mathrm{~h}$ (H\&E staining, magnification $\times 200$ ), with less hemorrhaging than in the SAP group; $\mathrm{E}$ - SS group after $12 \mathrm{~h}$ of the ileum (H\&E staining, magnification $\times 200$ ); F, G - SAP group after $12 \mathrm{~h}$ of the ileum (H\&E staining, magnification $\times 200$ ), with irregular villi, edema and hemorrhaging
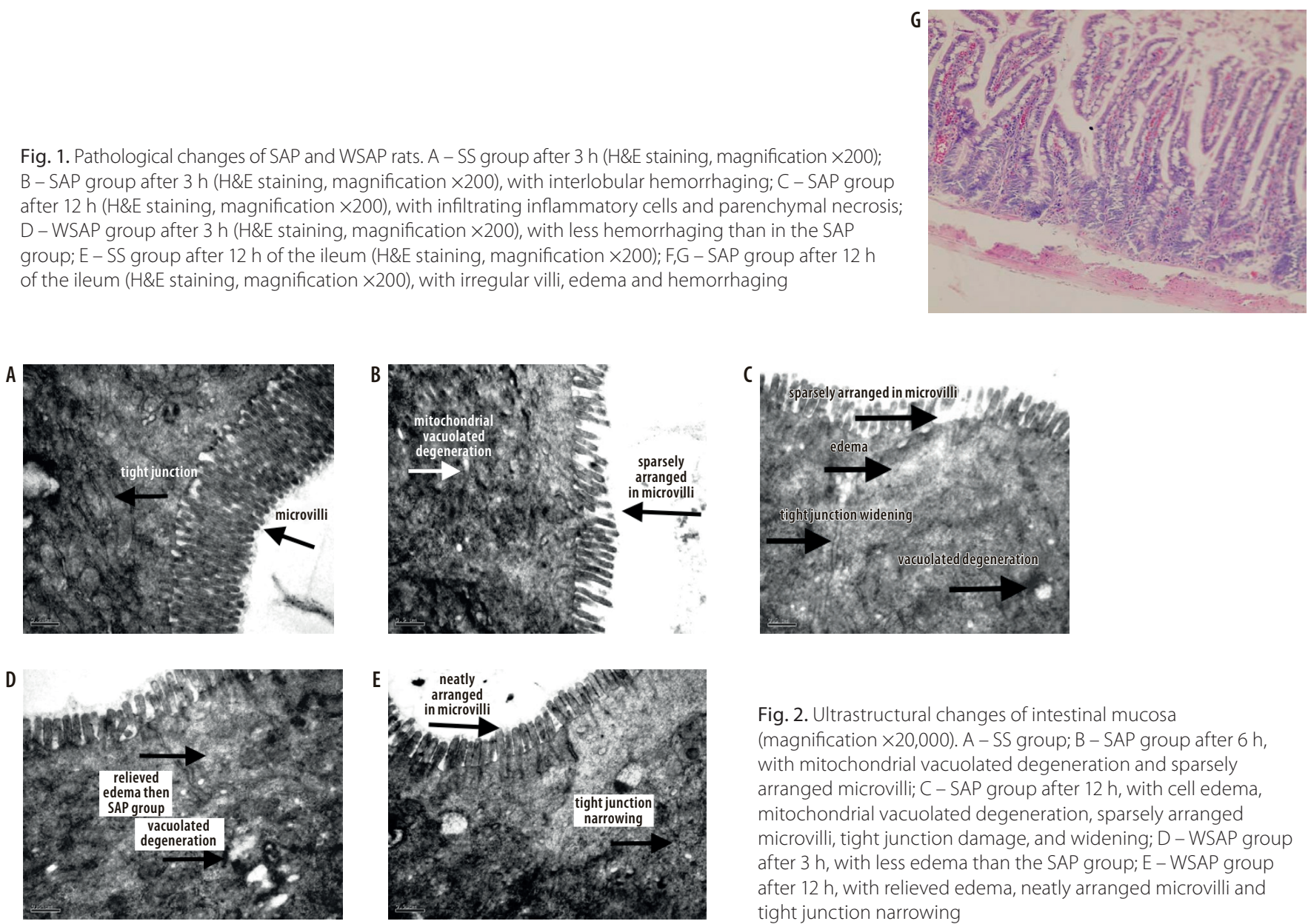

Fig. 2. Ultrastructural changes of intestinal mucosa (magnification $\times 20,000$ ). A - SS group; B - SAP group after $6 \mathrm{~h}$, with mitochondrial vacuolated degeneration and sparsely arranged microvilli; C - SAP group after $12 \mathrm{~h}$, with cell edema, mitochondrial vacuolated degeneration, sparsely arranged microvilli, tight junction damage, and widening; D - WSAP group after $3 \mathrm{~h}$, with less edema than the SAP group; $\mathrm{E}$ - WSAP group after $12 \mathrm{~h}$, with relieved edema, neatly arranged microvilli and tight junction narrowing

\section{The intestinal Evans blue results}

The SAP group ileal tissue Evans blue content was higher than the SS group $(92.06 \pm 5.24 \mu \mathrm{g} / \mathrm{g})(\mathrm{p}<0.01)$, showing increased intestinal mucosal permeability in the SAP group. However, compared with the SAP group, the Evans blue content was significantly lower in the WSAP group: $225.95 \pm 6.45 \mu \mathrm{g} / \mathrm{g}, 168.45 \pm 6.84 \mu \mathrm{g} / \mathrm{g}$ and $108.47 \pm 6.68 \mu \mathrm{g} / \mathrm{g}$ after $3 \mathrm{~h}, 6 \mathrm{~h}$ and $12 \mathrm{~h}$, respectively. This suggests that WT changes to intestinal permeability may be dose-dependent. 


\section{Western blot}

The total PKB protein expression was abundant in all 3 study groups. The differences were not statistically significant and did not change over time. The levels of $\mathrm{p}-\mathrm{PKB}$ were higher in the SAP group than in the SS group and they rose steadily from $3 \mathrm{~h}$ to $12 \mathrm{~h}$ after the procedure. However, PKB phosphorylation was significantly inhibited in the WSAP group, as in the $3 \mathrm{~h}, 6 \mathrm{~h}$ and $12 \mathrm{~h}$ subgroups. The content of p-PKB was lower in the WSAP group than in the SAP group and the difference was significant $(\mathrm{p}<0.05)$ (Fig. 3, Table 4).

\section{Discussion}

The pathogenesis of SAP is still poorly understood and has not been completely elucidated. Increasing evidence has demonstrated that the production and release of inflammatory mediators and other bioactive substances may play a significant role in systemic manifestations of SAP and is associated with remote organ dysfunction. ${ }^{15}$

PI3K is present in the cell, and its biological effects are extensive. It has been shown that PI3K can be activated to participate in signal transduction by a variety of inflammatory factors in inflammation, and that PKB is an important protease located downstream of PI3K, closely related to PI3K. PI3K can combine with the PH domain of PKB, phosphorylate it and cause further changes in the target genes in the nucleus; it regulates neutrophil activation and migration and the expression of inflammatory factors. Therefore, phosphorylation of PKB can be used as an activity indicator of PI3K. ${ }^{16}$ Fully active PKB/Akt mediates numerous cellular functions, including angiogenesis, metabolism, growth, proliferation, survival, protein synthesis, transcription, and apoptosis. ${ }^{17} \mathrm{PI} 3 \mathrm{~K}$ pathway activation is required for G1/S and G2/M phase progression, and constitutive activation of PI3K or PKB leads to reduced cyclin B synthesis and interferes with timely degradation of cyclin B1. ${ }^{18}$

A genetic or pharmacological blockade of the PI3K/PKB pathway in experimental animals can protect normal tissues against damage caused by inflammation. ${ }^{19}$ Inhibition of the PI3K/PKB pathway with a PI3K/PKB inhibitor decreased serum cytokine levels and increased the survival of mice subjected to sepsis. ${ }^{20}$ Research by Zhu et al. offers evidence that IPostC mediates cardioprotection in the remodeled rat myocardium, primarily via activation of the PI3K-PKB/Akt reperfusion injury salvage kinase pathway. ${ }^{21} \mathrm{PI} 3 \mathrm{Ks}$ are also involved in the pathogenesis of AP. Activation of the PI3K signaling pathway, and in particular of the class IB PI3KY isoform, plays a significant role in those events which are necessary for the initiation of acute pancreatic injury. ${ }^{18}$ Downregulation of the CSE/ $\mathrm{H} 2 \mathrm{~S}$ system plays an important role in SAP development and progression and in preconditioning the $\mathrm{H} 2 \mathrm{~S}$ donor with NaHS-induced anti-inflammatory activity in SAP.

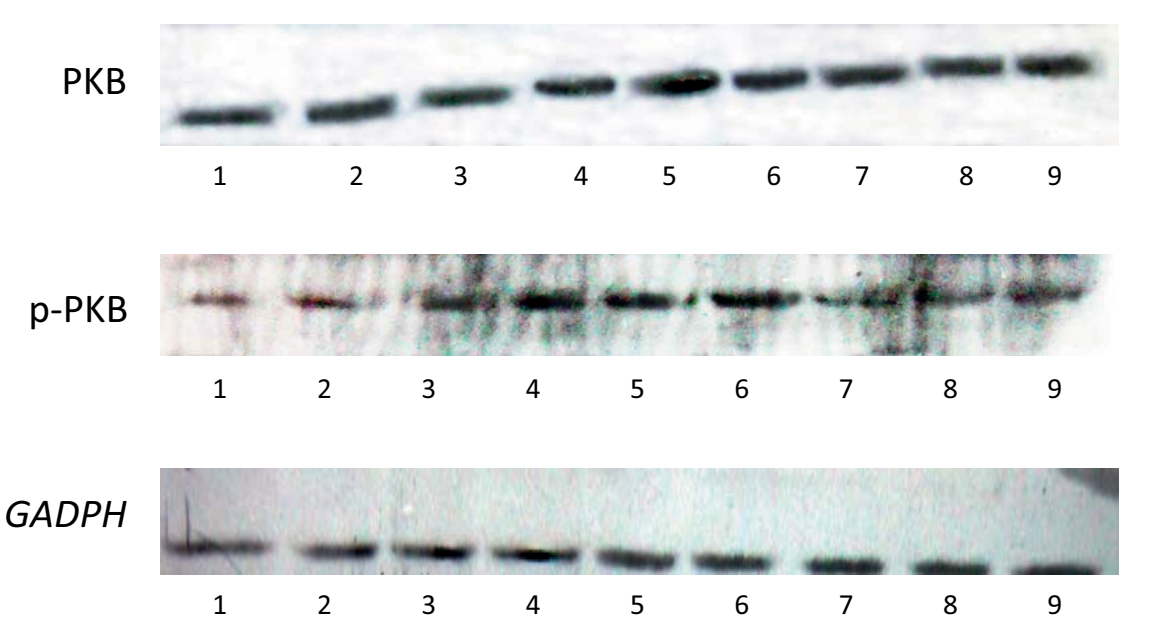

Fig. 3. The expression of PKB and p-PKB in the intestines of all study groups at different timepoints. The p-PKB levels were higher in the SAP group than in the SS group and they rose steadily between $3 \mathrm{~h}$ and $12 \mathrm{~h}$ after the operation. However, PKB phosphorylation was significantly inhibited in the WSAP group, as in its $3 \mathrm{~h}, 6 \mathrm{~h}$ and $12 \mathrm{~h}$ subgroups

1: SS group after $3 \mathrm{~h} ; 2$ : SS group after $6 \mathrm{~h}$; 3: SS group after $12 h$; 4 : SAP group after $3 h$; 5: SAP group after $6 \mathrm{~h} ; 6$ : SAP group after $12 \mathrm{~h}$; 7: WSAP group after $3 \mathrm{~h}$; 8: WSAP group after 6 h; 9: WSAP group after $12 \mathrm{~h}$.

Table 4. The expression of PKB and p-PKB compared with GADPH in the intestines of all trial study groups at different timepoints. The levels of $\mathrm{p}-\mathrm{PKB}$ content was higher in the SAP group than in the SS group, and continued to rise steadily from $3 \mathrm{~h}$ to $12 \mathrm{~h}$ after the operation. However, PKB phosphorylation was significantly inhibited in the WSAP group, also in $3 \mathrm{~h}, 6 \mathrm{~h}$ and $12 \mathrm{~h}$ subgroups. The content levels of p-PKB were lower in the WSAP group than in the SAP group, and the difference was significant $(p<0.05)$

\begin{tabular}{|l|c|c|c|c|c|c|}
\multirow{2}{*}{ Group } & \multicolumn{3}{|c|}{$3 \mathrm{~h}$} & \multicolumn{2}{c|}{$6 \mathrm{~h}$} & $12 \mathrm{~h}$ \\
\cline { 2 - 6 } Pathway & PKB/GADPH & $\mathrm{p}-\mathrm{PKB} / G A D P H$ & PKB/GADPH & $\mathrm{p}-\mathrm{PKB} / G A D P H$ & PKB/GADPH \\
\hline SS & $1.54 \pm 0.61$ & $0.68 \pm 0.09$ & $1.42 \pm 0.63$ & $0.82 \pm 0.20$ & $1.46 \pm 0.72$ \\
\hline SAP & $1.65 \pm 0.54$ & $1.25 \pm 0.33^{\#}$ & $1.48 \pm 0.62$ & $1.62 \pm 0.54^{\#}$ & $1.52 \pm 0.66$ \\
\hline WSAP & $1.49 \pm 0.80$ & $0.98 \pm 0.21^{\# *}$ & $1.55 \pm 0.47$ & $0.98 \pm 0.36^{\# *}$ & $1.58 \pm 0.73$ \\
\hline
\end{tabular}

${ }^{*} p<0.05$, compared to the control group; ${ }^{*} p<0.05$, compared to the SAP group. 
This protective effect was associated with PI3K/PKB phosphorylation inhibition. ${ }^{22}$

The fungal metabolite WT and the synthetic compound LY294002 are the 2 currently known inhibitors that show a fairly high specificity for PI3K. It has been shown that WT causes 95\% inhibition of PI3K and that the concentration required to induce apoptosis of cells maintained in growth factors correlates closely with that required for PI3K inhibition. ${ }^{23}$

Wortmannin is a commonly used cell biology reagent and has been previously used to inhibit DNA repair, receptormediated endocytosis and cell proliferation. ${ }^{24}$ Wortmannin has been shown to be effective in decreasing serum cytokine levels and increasing the survival of mice subjected to sepsis. ${ }^{20}$ It has also been shown to markedly reduce the subcellular redistribution of cathepsin B in an AP rat model..$^{25}$ Doses of WT markedly reduced trypsinogen activation in vitro and in vivo during the early stages of secretagogueinduced pancreatitis. ${ }^{16}$ Furthermore, WT treatment decreases inflammatory cytokines in SAP. ${ }^{26} \mathrm{Ng}$ et al. ${ }^{27}$ found that dosages of $0.175 \mathrm{mg} / \mathrm{kg}, 0.35 \mathrm{mg} / \mathrm{kg}$ or $0.7 \mathrm{mg} / \mathrm{kg}$ of WT inhibited PKB/Akt phosphorylation in a time- and dose-dependent manner, reaching a plateau at $4 \mathrm{~h}$ and at $0.7 \mathrm{mg} / \mathrm{kg}$. Abliz et al. ${ }^{28}$ demonstrated that $2 \mathrm{mg} / \mathrm{kg}$ of WT attenuates the thyroid injury associated with SAP in rats. Findings of Xu et al. showed that $1 \mathrm{mg} / \mathrm{kg}$ of WT decreases inflammatory cytokines in SAP rats. ${ }^{13}$ Ding's study ${ }^{29}$ suggests that a dosage of $0.35 \mathrm{mg} / \mathrm{kg}$ of WT is better for SAP rats than $1.4 \mathrm{mg} / \mathrm{kg}$ because of toxicity; thus, we chose a dosage of $0.35 \mathrm{mg} / \mathrm{kg}$ of WT to induce SAP in the WSAP rats.

Intestinal barrier dysfunction is now considered to be a major cause of complications such as bacterial translocation and MODS in SAP. Infection of pancreatic and peripancreatic tissues is considered to originate from the intestine..$^{30,31}$

Samel et al. ${ }^{32}$ demonstrated that bacterial translocation occurs within $3 \mathrm{~h}$ of the induction of pancreatitis in rats. Meriläinen et al. found that claudins mostly seem to remain unaltered during the early phase of the disease, but there is evidence of decreased claudin-3, claudin-4 and claudin-7 in acute necrotic pancreatitis, which may lead to tight junction disruption and bacterial translocation during the late course of the disease. ${ }^{6}$ Tian et al. demonstrated that tumor necrosis factor $\alpha$ (TNF- $\alpha$ )-regulated miR-155 overexpression inhibits apical junction complex (AJC) component protein syntheses of ZO-1 and E-cadherin by downregulating post-transcriptional RhoA expression, and that it disrupts the intestinal epithelial barrier in experimental SAP. ${ }^{8}$ Thus, tight junction disruption and intestinal bacterial translocation are important factors that lead to SAP.

In our study, the SS group was observed under $\mathrm{H} \& \mathrm{E}$ staining to have complete lobular structures, no bleeding or necrosis, and no inflammatory cell infiltration. The SAP rats displayed hemorrhaging, edema, parenchymal necrosis, and infiltrating inflammatory cells. However, the WSAP group showed milder pancreatic pathological damage than the SAP group, with significantly lower histopathological scores after $3 \mathrm{~h}, 6 \mathrm{~h}$ and $12 \mathrm{~h}(\mathrm{p}<0.05)$. The morphological changes of the pancreas, including pancreatic edema, necrosis, hemorrhaging, and inflammation, were scored according to Spormann's criteria. ${ }^{14}$ The WSAP group also exhibited lighter ultrastructural changes to the intestinal mucosa compared with the SAP group, which suggests that WT relieves the damage in SAP rats. The SAP group displayed mitochondrial vacuolated degeneration, sparsely arranged microvilli, cell edema, and tight junction widening. However, the WSAP group rats were observed to have neatly arranged microvilli, tight junction narrowing and less edema.

In addition, the intestinal mucosal permeability was higher in the SAP group. However, the Evans blue content was significantly lower in the WSAP group than in the SAP group. This suggests that WT changes to intestinal permeability maybe dose-dependent. A microbiological evaluation of bacterial translocation in SAP may directly support our findings.

The results of western blotting showed that PKB phosphorylation was significantly inhibited in the WSAP group, as in its $3 \mathrm{~h}, 6 \mathrm{~h}$ and $12 \mathrm{~h}$ subgroups, and that the content of $\mathrm{p}-\mathrm{PKB}$ was lower in the WSAP group than in the SAP group. Our study suggests that WT relieves intestinal permeability changes in SAP rats. The results of western blotting show that the levels of $\mathrm{p}-\mathrm{PKB}$ were lower in the WSAP group than in the SAP group. It is possible that the PI3K/PKB signal transduction pathway may involve SAP intestinal injuries and that WT may relieve SAP intestinal injuries through the PI3K/PKB pathway.

\section{References}

1. Zhao G, Zhang JG, Wu HS, et al. Effects of different resuscitation fluid on severe acute pancreatitis. World J Gastroenterol. 2013;19(13): 2044-2052.

2. Fritz S, Hackert T, Hartwig W, et al. Bacterial translocation and infected pancreatic necrosis in acute necrotizing pancreatitis derives from small bowel rather than from colon. Am J Surg. 2010;200(1):111-117.

3. Sun $X$, Shao $Y$, Jin $Y$, et al. Melatonin reduces bacterial translocation by preventing damage to the intestinal mucosa in an experimental severe acute pancreatitis rat model. Exp Ther Med. 2013;6(6): 1343-1349.

4. Li JP, Yang J, Huang JR, et al. Immunosuppression and the infection in patients with early SAP. Front Biosci. 2013;18:892-900.

5. Liang HY, Chen T, Yan HT, Huang Z, Tang LJ. Berberine ameliorates severe acute pancreatitis induced intestinal barrier dysfunction via a myosin light chain phosphorylation dependent pathway. MolMed Rep. 2014;9(5):1827-1833.

6. Meriläinen S, Mäkelä J, Koivukangas V, et al. Intestinal bacterial translocation and tight junction structure in acute porcine pancreatitis. Hepatogastroenterology. 2012;59(114):599-606.

7. Tian R, Tan JT, Wang RL, Xie H, Qian YB, Yu KL. The role of intestinal mucosa oxidative stress in gut barrier dysfunction of severe acute pancreatitis. Eur Rev Med Pharmacol Sci. 2013;17(3):349-355.

8. Tian R, Wang RL, Xie H, Jin W, Yu KL. Overexpressed miRNA-155 dysregulates intestinal epithelial apical junctional complex in severe acute pancreatitis. World J Gastroenterol. 2013;19(45):8282-8291.

9. Sharma B, Srivastava S, Singh N, Sachdev V, Kapur S, Saraya A. Role of probiotics on gut permeability and endotoxemia in patients with acute pancreatitis: A double-blind randomized controlled trial. J Clin Gastroenterol. 2011;45(5):442-448. 
10. Deitch EA, Senthil M, Brown M, et al. Trauma-shock-induced gut injury and the production of biologically active intestinal lymph is abrogated by castration in a large animal porcine mode. Shock. 2008; 30(2):135-141.

11. Luo J, Huang B, Zhang Z, Liu M, Luo T. Delayed treatment of propofol inhibits lipopolysaccharide-induced inflammation in microglia through the PI3K/PKB pathway. Neuroreport. 2018;29(10):839-845.

12. Qiao X, Gai H, Su R, et al. PI3K-AKT-GSK3 $\beta$-CREB signaling pathway regulates anxiety-like behavior in rats following alcohol withdrawal. J Affect Disord. 2018;235:96-104.

13. Xu P, Wang J, Yang ZW, Lou XL, Chen C. Regulatory roles of the PI3K/ Akt signaling pathway in rats with severe acute pancreatitis. PLoS One. 2013;8(11):e81767.

14. Spormann H, Sokolowski A, Letko G. Effect of temporary ischemia upon development and histological patterns of acute pancreatitis in the rat. Pathol Res Pract. 1989;184(5):507-513.

15. Bhatia M, Neoptolemos JP, Slavin J. Inflammatory mediators as therapeutic targets in acute pancreatitis. Curr Opin Investig Drugs. 2001;2(4): 496-501.

16. Lin $\mathrm{CH}$, Yeh $\mathrm{SH}$, Lin $\mathrm{CH}$. A role for the PI-3 kinase signaling pathway in fear conditioning and synaptic plasticity in the amygdale. Neuron. 2001;31(5):841-851.

17. Hemmings BA, Restuccia DF. PI3K-PKB/Akt pathway. Cold Spring Harb Perspect Biol. 2012;4(9):a011189.

18. Liang J, Slingerland JM. Multiple roles of the PI3K/PKB (Akt) pathway in cell cycle progression. Cell Cycle. 2003;2(4):339-345.

19. Cantley LC. The phosphoinositide 3-kinase pathway. Science. 2002; 296(5573):1655-1657.

20. Yadav UC, Naura AS, Aguilera-Aguirre L, et al. Aldose reductase inhibition prevents allergic airway remodeling through PI3K/AKT/GSK3beta pathway in mice. PLoS One. 2013;8(2):e57442.

21. Zhu M, Feng J, Lucchinetti E, et al. Ischemic postconditioning protects remodeled myocardium via the PI3K-PKB/Akt reperfusion injury salvage kinase pathway. Cardiovasc Res. 2006;72(1):152-162.

22. Rao $C Y, F u L Y, H u C L$, et al. $H 2 S$ mitigates severe acute pancreatitis through the PI3K/AKT-NF-KB pathway in vivo. World J Gastroenterol. 2015;21(15):4555-4563.
23. Yao R, Cooper GM. Requirement for phosphatidylinositol 3-kinase in the prevention of apoptosis by nerve growth factor. Nature. 1995; 267(5206):2003-2006.

24. Liu Y, Shreder KR, Gai W, Corral S, Ferris DK, Rosenblum JS. Wortmannin, a widely used phosphoinositide 3-kinase inhibitor, also potently inhibits mammalian polo-like kinase. Chem Biol. 2005;12(1):99-107.

25. Kim SH, Jang YW, Hwang P, Kim HJ, Han GY, Kim CW. The reno-protective effect of a phosphoinositide 3-kinase inhibitor wortmannin on streptozotocin-induced proteinuric renal disease rats. Exp Mol Med. 2012;44(1):45-51.

26. Rogers Lynette K, Xu P, Wang J, Yang ZW, Lou XI, Chen C. Regulatory roles of the PI3K/Akt signaling pathway in rats with severe acute pancreatitis. PLoS One. 2013;8(11):e81767.

27. Ng SS, Tsao MS, Nicklee T, Hedley DW. Wortmannin inhibits pkb/ akt phosphorylation and promotes gemcitabine antitumor activity in orthotopic human pancreatic cancer xenografts in immunodeficient mice. Clin Cancer Res. 2001;7(10):3269-3275.

28. Abliz A, Deng W, Sun R, Guo W, Zhao L, Wang W. Wortmannin, PI3K/ Akt signaling pathway inhibitor, attenuates thyroid injury associated with severe acute pancreatitis in rats. Int J Clin Exp Pathol. 2015;8(11): 13821-13833.

29. Ding RK. The Role of PI3K/PKB Signal Pathway and its Inhibitor Wortmannin in Renal Injuries Induces by Severe Acute Pancreatitis in Rats. PhD dissertation 2011, Hebei Medical University, China.

30. Schwarz M, Thomsen J, Meyer H, Buchler MW, Beger HG. Frequency and time course of pancreatic and extrapancreatic bacterial infection in experimental acute pancreatitis in rats. Surgery. 2000;127(4): 427-432.

31. Chen J, Huang C, Wang J, et al. Dysbiosis of intestinal microbiota and decrease in paneth cell antimicrobial peptide level during acute necrotizing pancreatitis in rats. PLoS One. 2017;12(4):e0176583.

32. Samel S, Lanig S, LuxA, et al. The gut origin of bacterial pancreatic infection during acute experimental pancreatitis in rats. Pancreatology. 2002;2(5):449-455. 